\section{REFLEXIONES SOBRE LA CRECIENTE CONGESTIÓN DE LA ADMINISTRACIÓN DE JUSTICIA EN MATERIA CIVIL PARA EL CASO COLOMBIANO*}

\section{Luis Agapito Moreno Moreno \\ Universidad Militar Nueva Granada}

Fecha de recepción: 19 de agosto de 2009

Fecha de aprobación: 18 de septiembre de 2009

\section{Resumen}

Existe una bomba de tiempo en la administraExiste una bomba de tiempo en la administración de justicia en materia civil. Siendo este un Servicio público de carácter fundamental según la Carta Política, no es concebible que el Honorable Consejo Superior de la Judicatura en sus largos dieciocho años de existencia, no haya creado mecanismos apropiados y efectivos para que los Despachos Judiciales puedan cumplir el precepto constitucional de una pronta y cumplida administración de justicia.

\section{Palabras clave}

Congestión judicial, Administración de la justicia, Términos de procedimiento, reforma integral, código de procedimiento civil, servicio público

\section{REFLECTIONS ON THE GROWING CONGESTION OF THE ADMINISTRATION OF JUSTICE IN CIVIL CASE FOR COLOMBIAN}

\begin{abstract}
There is a time bomb in the administration of justice in civil matters. Since this is a public service of a fundamental nature as the Constitution, it is conceivable that the Honorable Supreme Judicial Council in its long eighteen years of existence has not established appropriate and effective mechanisms for judicial offices to meet the constitutional precept prompt and complete administration of justice.
\end{abstract}

\section{Key words}

Congestion judicial administration of justice, procedural terms, comprehensive reform, civil procedure code, public service

\section{INTRODUCCIÓN}

La congestión judicial genera lentitud y retraso al momento de acudir ante la jurisdicción a la hora de dirimir un conflicto; lo que trae como consecuencia la pérdida de credibilidad en la agilidad de decisión de la administración de justicia en materia civil.

A partir de 1991 se implementa en Colombia cambios en la administración de la Rama Judicial. Uno de los frentes a atacar en la reforma judicial ha sido la modernización del sistema judicial con el fin de aumentar la eficiencia, la eficacia, la equidad y la previsibilidad en la resolución de conflictos. (Ariza Zabala, 2003)

La investigación tiene como fundamento principal mostrar la presunta bomba de tiempo latente al interior de la administración de justicia; es claro que la administración de justicia es una función pública de carácter fundamental 
según lo establecido por la Carta Política. La misma es clara al precisar en su artículo 228 que:

"La administración de justicia es función pública. Sus decisiones son independientes. Sus actuaciones serán públicas y permanentes, con las excepciones que establezca la ley y en ellas prevalecerá el derecho sustancial. Los términos procesales se observan con diligencia y su incumplimiento será sancionado. Su funcionamiento será desconcentrado y autónomo" (República de Colombia, 2008, Art. 228).

La norma constitucional citada establece los parámetros bajo los cuales debe desarrollarse correctamente la administración de justicia; en este orden de ideas hay congestión en la administración de justicia en materia civil porque el aparato judicial establecido para ello no ha sido capaz de atender las necesidades de aquellos que han acudido a la jurisdicción puesto que el numero de demandas presentadas por los usuarios superan la capacidad de los empleados de la administración de justicia lo que impide que se puedan resolver oportunamente dichas demandas.

La investigación busca establecer la realidad de la congestión judicial que existe al interior de la rama, no para quedarnos apacibles ante una inminente problemática de carácter social como la que se esta viviendo, por el contrario como resultado de la investigación es nuestro objetivo presentar recomendaciones y alternativas que permitan una posible reforma integral al actual Código de Procedimiento Civil, en búsqueda de un resurgimiento de la Jurisdicción para hacer realidad aquello que la Carta Política ha determinado como pronta y cumplida administración de justicia y lo que es más importante llegar a recuperar la credibilidad en la justicia por parte de la sociedad.

Se empieza por determinar quienes son actores activos en la investigación, ubicando así un espacio teórico practico definido en el que se pueda orientar la discusión sobre la congestión de la justicia y a partir del cual podamos dar respuesta a interrogantes tales como: ¿En donde se genera la congestión?, ¿Por qué se genera la congestión? ¿Y cuales los factores que inciden en este flagelo?

\section{MARCO REFERENCIAL DE LA REFLEXIÓN}

Para lo anterior hemos partido de un marco histórico legal y conceptual, así como un diseño metodológico de tipo descriptivo que nos permita realizar un estudio cuantitativo del tiempo que con lleva un Proceso Civil desde la demanda hasta la sentencia debidamente ejecutoriada en diez (10) Juzgados Civiles Municipales y diez (10) del Circuito de Bogotá.

Para entender estos requerimientos de investigación hemos llevado a cabo un proceso metodológico que combina las entrevistas a funcionarios, abogados, estudiantes de derecho, litigantes y usuarios de la justicia; de tal suerte que nos permitan validar la información y analizar las fortalezas y debilidades del sistema actual, para luego hacer un diagnóstico que permita dar y proponer las mejores soluciones sin mayor esfuerzo por parte del Estado, entiéndase que este ha sido, es y será el talón de Aquiles del poder judicial.

\subsection{Marco histórico legal}

El marco referente de la Carta Magna al tener como imperativo que los términos procesales se deben observar con diligencia y su incumplimiento será sancionado, no se cumple en la actualidad por parte de la mayoría de Juzgados, basta observar como en la etapa probatoria de un proceso ordinario general el Código de Procedimiento Civil vigente en el inciso segundo del articulo 402 determina que las pruebas 
deben practicarse en un termino de 40 días y la realidad judicial es que en la inmensa mayoría de Juzgados Civiles las fechas para practicar las pruebas se dan para $3,4,6$ y hasta 10 meses después del auto que las decreta, violando así todos los días el mandato constitucional, y El Consejo Superior de la Judicatura se ha limitado a nombrar Jueces y Magistrados de Descongestión en forma transitoria y sin que hasta la fecha se haya dado una solución de fondo con resultados positivos para una sociedad que clama y reclama justicia cada día.

Partiendo de la Etnia Muisca con el Código de Nemequeme, pasando por las constituciones de Cundinamarca y Tunja en 1811, relativas a la Administración de Justicia; normas recogidas en 1812 y 1815 por las Constituciones de Cartagena, Antioquia, Mariquita y Neiva y solo hasta 1821 con la expedición de la Constitución de Colombia empezó la labor legislativa dentro del campo Procesal.

Es así como mediante Decreto 1822 se crea una comisión para presentar proyectos de legislación análoga a la Republica, para que basados en legislaciones Europeas y Españolas redactaran un proyecto de Legislación en materia Procedimental acta para la República.

La Ley 10 de Julio de 1824 estableció la forma de conocer las causas en materia de comercio, luego en el mismo año se creó el Arancel Judicial que debían cobrar los Juzgados y Tribunales de la Republica, mientras que en 1825 se estableció la incorporación de Abogados al sistema y en este mismo año se organizó el Poder Judicial garantizando desde entonces la pronta y cumplida Administración de Justicia, con base en un número suficiente de Tribunales y Juzgados. (Externado de Colombia, Historia del Derecho Procesal Civil 1987).

La Ley 13 de Mayo de 1825 se refirió específicamente al Procedimiento Civil en Tribunales y Juzgados de la Republica, considerada esta Ley como el primer estatuto de Procedimiento Civil en Colombia.

En 1845 apareció la famosa Republica Granadina elaborada por Lino De Pombo, en cuyo tomo II se determina y condensa el aspecto procesal, adicionado en 1850. (Hernán Fabio López Blanco, Tomo I/ 2005).

En el año 1958 nuestro país adopto el sistema de Gobierno Federal y el Estado Soberano de Cundinamarca promulgó en el mismo año la Ley 29 Orgánica del Poder Judicial, el cual regulaba el Procedimiento Civil, siendo esta Ley una copia textual del Código Civil Chileno y a su vez copia de la Ley de Enjuiciamiento Civil Española de 1855.

Luego para el año de 1872 se adoptó el Código Judicial de Cundinamarca como Código de la Unión, dándole a este Estatuto un carácter Nacional.

Posteriormente nuestro país regresa al centralismo y se promulga la Ley 75 de 1877, acogiendo para la Republica de Colombia el Código Judicial de 1872, vale decir el mismo Código de Cundinamarca de 1858 y por ende el Español de Enjuiciamiento Civil de 1855.

A partir de 1887 ante la necesidad de modernizar las Instituciones Jurídicas se expidió un sin número de Leyes que reformaron y derogaron normas del antiguo Código de Cundinamarca, presentándose así un caos normativo en cuanto a su vigencia.

Para 1923 se promulgó la Ley 103 o Código Ismael Arbeláez y Don José Antonio Archila quien se encargo de publicar el Código de Organización Judicial y Procedimiento Civil, solo se limito a comentar los antecedentes legislativos incurriendo en contradicciones entre la Ley sustancial y la Procesal; concluyendo que el Código de la Unión de 1872 dio pie para promulgar la importante Ley 57 de 1887 denominada como 
el Código de la Nueva Republica de Colombia de Raigambre Española.

Infortunadamente la Ley 26 de 1924 suspendió indefinidamente la vigencia de la Ley 103 y dispuso continuar la vigencia de la Ley anterior esto es la Ley 57 de 1887, vale decir el Antiguo Código del Estado de Cundinamarca de 1858 con todas su Reformas.

Concluimos en esta parte con el Código Judicial de 1931 que incluyó tres libros, así: Organización Jurisdiccional, Procedimiento Civil y el Penal, que a la postre solo llevo a hacer prevalecer el de Procedimiento Civil al adoptarse como Ley de la República con vigencia hasta Junio de 1971. (Hernán Fabio López Blanco, 2005).

Es así como el legislador colombiano cronológicamente ha realizado e implementado reformas al Código de Procedimiento Civil a fin de hacer más eficiente la administración de justicia; el desarrollo de las reformas ha sido el siguiente:

En Agosto 6 y Octubre 2 de 1970 el Ejecutivo de entonces investido de facultades extraordinarias concedidas por la Ley 4 de 1969 dictó los Decretos números 1400 y 2019 por los cuales expidió el Código de Procedimiento Civil vigente, desde luego con la asesoría de Cognotados Juristas como los extintos Hernando Devis Echandía y Hernando Morales Molina entre otros. Esta reforma introdujo importantes modificaciones al sistema anterior que se creía excesivamente formalista, por lo que la Reforma otorgo al Juez amplias facultades de intervención como director del proceso, cambiando la repudiada tarifa legal de pruebas, implantando parcialmente la oralidad y reduciendo el número de procedimientos especiales, por lo que el Decreto 2019 del mismo año solo sirvió para morigerar puntos de redacción del Código, sin embargo desde su vigencia se evidenció la inaplicación de algunas normas y el incremento de morosidad de la Justicia.
Mediante la Ley 30 de Octubre 9 de 1987, el Congreso de la República otorgó facultades al Ejecutivo por dos años para reformar la Administración de Justicia y se expidieron varios Decretos, así: (Anales del Congreso 1987).

Desde el año de 1988 hasta 1991 se expidieron distintos Decretos a fin de hacer cada vez más eficiente la actividad de la rama judicial en material Civil. El primero de ellos es el Decreto No 902 de 1988, por medio del cuál se autorizó el trámite Notarial de las Sucesiones cuando son de común acuerdo por parte de todos los interesados; a continuación de este se implemento también el trámite notarial para la corrección de errores en las actas de registro civil sale el Decreto No 999 de 1988, dando así paso a la instauración de las instituciones de la separación de cuerpos y divorcio del Matrimonio Civil a través de los decretos $\mathrm{N}^{\mathrm{o}} 2458 \mathrm{de}$ 1988 y No 1900 de 1989.

Otros decretos importantes que deben ser tenidos en cuenta dentro del desarrollo histórico de la jurisdicción civil son el Decreto No 2279 de 1989, que reglamento un proceso Arbitral Autónomo en reemplazo al regulado por el Código de Procedimiento Civil; el Decreto No 2282 de 1989 el cual reformó el Código de Procedimiento Civil vigente en 372 artículos parciales y entró en vigencia el 1 de Julio de 1990.

En cuanto a las leyes expedidas tenemos la Ley 446 de 1988, denominada Estatuto Arbitral por la cual se adopta como legislación permanente algunas normas del Decreto 2651 de 1991, se modifican algunas del Código de Procedimiento Civil, se derogan otras de la Ley 23 de 1991 y Decreto 2279 de 1989, se modifican y expiden normas del Código Contencioso Administrativo y se dictan otras disposiciones sobre Descongestión, eficiencia y acceso a la Justicia.

Lo anterior llego a ser insuficiente así que en el año de 1998 el Decreto $N^{\circ} 1818$ de 1998 crea el 
estatuto de los mecanismos alternativos de solución de conflictos (conciliación, arbitramento y amigable composición). Lo cual a pesar de ser efectivo no contribuyo en mucho, lo que trae como resultado la expedición Acuerdo $\mathrm{N}^{\mathrm{o}}$ 433 de 1999 en el que se reglamento el cierre extraordinario de Despachos Judiciales. Se intenta una nueva reforma que hasta la fecha no ha tenido validez alguna, y es aquella en la que se crearon los Juzgados Civiles del Circuito Especializados en Derecho Comercial con el Decreto N $^{\circ} 2270$ de 1989.

Por seguir siendo insuficientes los decretos desarrollados nace la Ley 25 de 1992 reglamentando el Divorcio del Matrimonio Civil y la Cesación de los Efectos Civiles del Matrimonio Religioso. En búsqueda de hacer más eficiente el trabajo de la rama se involucra al interior a los estudiantes de derecho a través del Acuerdo $\mathrm{N}^{\circ} 523$ de 1999 por medio del cual se reglamenta la realización de actividades por parte de estudiantes de derecho en los Despachos Judiciales como equivalentes a las prácticas del pensum académico. Procura que los estudiantes de Derecho de las Universidades oficialmente reconocidas puedan realizar las prácticas judiciales en cualquier Despacho Judicial para colaborar en su descongestión. El anterior adicionado por el Acuerdo $N^{\circ} 719$ de 2000, por medio del cual se reglamenta la práctica de los estudiantes de derecho en la Corte Constitucional, Corte Suprema de Justicia, Consejo Superior de la Judicatura, Consejo de Estado, Tribunales Superiores y Administrativos, Consejos Seccionales de la Judicatura, Oficinas Judiciales de apoyo y de servicios de las Direcciones Seccionales de la Rama Judicial.

En el año 2003 se hace necesaria una nueva reforma al Código de Procedimiento Civil mediante la Ley 794 de 2003 la cual también regula el proceso ejecutivo y se dictan otras disposiciones.
Decreto $N^{\circ} 890$ de 2003, reglamenta el artículo 58 de la ley 794 de 2003, que modifica el artículo 528 del Código de Procedimiento Civil y autoriza comisionar a los Notarios, Cámaras de Comercio o al Banco Popular sucursal martillo legalmente autorizado, dentro o fuera de la sede del Juzgado para adelantar la diligencia de remate. (Diario Oficial).

\subsection{Marco Teórico}

La inmensa mayoría de conflictos civiles son tramitados en Colombia a través de dos tipos de procesos: los declarativos y los ejecutivos, los primeros tienen como objeto el reconocimiento judicial de la existencia de un derecho. En este tipo de juicio las partes, debaten hechos y aportan pruebas encaminadas a establecer una situación jurídica incierta; por el contrario en los procesos ejecutivos se busca hacer efectivo el cumplimiento de una obligación clara, expresa y exigible, derivada de un documento (titulo ejecutivo) que el demandante debe aportar al expediente. Es a través de estos procesos que, como ejemplo, se tramitan los cobros de deudas garantizadas con títulos valores, como cheques y pagarés. (UPRIMNY, 2000).

Luego de relatados los principales conflictos que teórica y prácticamente deben ser resueltos por la jurisdicción civil, se pasa a relacionar una serie de teorías de vital importancia en su desarrollo.

\section{LA TEORÍA DEL DERECHO CONCRETO} DE OBRAR, nos indica, que la acción, que constituye un poder jurídico para solicitar la intervención del Estado, únicamente la tiene el que haya basado en el derecho material su pretensión, es decir, que solo quien esté asistido del derecho sustancial puede presentar una demanda al Estado para que éste la resuelva.

\section{LA TEORÍA DEL DERECHO ABS-} TRACTO, sostenida por FRANCESCO 
CARNELUTTI, quien manifiesta que la acción la tiene no solamente quien, en cada caso concreto, está asistido por el derecho subjetivo material, sino que es un derecho totalmente independiente de aquel, ya que no persigue una sentencia favorable sino un proceso en el cual se resuelva sobre la pretensión del demandante (Carnelutti, 2000).

\section{LA TEORÍA DE LA ACCIÓN COMO DERECHO POTESTATIVO, Sostenida por} CHIOVENDA quien afirma que "la acción es un poder que corresponde frente al adversario, respecto al cual se produjo el efecto jurídico de la actuación de la ley. El adversario no está obligado a ninguna cosa frente a este poder, está simplemente sujeto a él. La acción se agota con su ejercicio, sin que el adversario pueda hacer nada para impedirla, ni para satisfacerla". (Chiovenda 1995)

\section{LA TEORÍA DE LA FACULTAD DEL DERECHO DE LA PERSONALIDAD, es la} doctrina expuesta por KHOLER, que le asigna a la acción la naturaleza de simple facultad y le niega el carácter de derecho autónomo. "La acción viene a ser la facultad, emanada del derecho a la integridad de la propia personalidad o derecho a la libertad, que toda persona tiene de dar vida a la demanda judicial dirigida contra el adversario y que produce el efecto de colocar a éste en la situación jurídica que con ella se origina, de la que nacen a su vez relaciones procesales, pero únicamente entre las partes.". (Hernando Devis Echandia, Tomo I 1994)

\section{EL DERECHO DE CONTRADICCIÓN en} cuanto al objeto encontramos que el mismo no es perseguir una tutela concreta mediante una sentencia favorable al demandado o imputado (excepción), sino la tutela abstracta por una sentencia justa y legal, cualquiera que sea y la oportunidad de ser oído en el proceso para el ejercicio del derecho a la defensa en igualdad de condiciones, facultades y cargas (acción en sentido negativo). (Hernando Morales Molina 1983)
EL TÉRMINO PROCESO desde el punto de vista etimológico es el vocablo que proviene del latín PROCESUS I PROCEDERE, que significa marchar, avanzar, desarrollar, llevar a cabo y en su acepción corriente puede concebirse como la serie o conjunto de actos tendientes a lograr un fin determinado, vale decir, un fin social.

\section{LA TEORÍA DEL PROCEDIMIENTO Y} PROCESO, consiste en normas reguladoras para la actuación ante los organismos jurisdiccionales ya sean civiles, de familia, laborales, penales, etc. (Diccionario Jurídico).

CARNELUTTI, quien fue tal vez el primero que hizo la distinción entre proceso y procedimiento, concibió aquel como "la suma de los actos que se realizan para la composición del litigio" y este como el "orden y la sucesión de su realización". El proceso es el continente; mientras que el procedimiento es el contenido, por cuanto es posible agotar el proceso mediante un solo procedimiento, pero también el proceso puede comprender varios procedimientos, como acontece con las varias actuaciones e instancias que usualmente lo integran.

LOS TÉRMINOS son plazos señalados por la ley o por el juez para que dentro de ellos se dicten las providencias, se haga uso de un derecho o se ejecute algún acto en el curso de un proceso. Los términos están instituidos para todos quienes intervienen dentro del proceso, las partes, los terceros, el juez y aún los secretarios. (Código de Procedimiento Civil Comentado, Legis 2007).

LAS NOTIFICACIONES, significan hacer saber, hacer conocer y es en este sentido en el que se toma en el derecho procesal el vocablo notificación, pues se quiere indicar que se ha comunicado a las partes y terceros autorizados para intervenir en el proceso las providencias judiciales que dentro de él se profieren. 
LA IMPUGNACIÓN, proviene del latín impugnare que significa atacar; acción y efecto de atacar, tachar o refutar un acto judicial, documento, deposición testimonial, informe de peritos, etc., con el objeto de obtener su revocación o invalidación; en cuanto al aspecto procesal y en su acepción más amplia, son los medios de que disponen las partes para atacar las providencias jurisdiccionales cuando son contrarias a derecho o sencillamente equivocadas. (Código de Procedimiento Civil, Leyer 2007).

EL DEBIDO PROCESO, es un principio de carácter constitucional procesal según el cual toda persona natural o jurídica tiene derecho a comparecer y hacer uso de la jurisdicción cuando considere que le ha sido vulnerados sus derechos o incumplido sus obligaciones de tal suerte que se le otorguen las garantías constitucionales del debido proceso, se respete el derecho de defensa y se mantenga la igualdad de las partes.

El debido proceso se aplicara a toda clase de actuaciones judiciales o administrativas de tal suerte que nadie pueda ser juzgado sino conforme a leyes preexistentes al acto que se le atribuye o imputa, ante Juez o Tribunal competente y con observancia de la plenitud de las formas propias de cada proceso y procedimiento, esto es de cada juicio. (Art. 29 Constitución Política 91) (Art. 4 Código de Procedimiento Civil 2008).

\section{LA ADMINISTRACIÓN DE JUSTICIA,} es una función pública, sus decisiones son independientes, las actuaciones serán públicas y permanentes con las excepciones que establezca la Ley (vacaciones colectivas). En la administración de justicia prevalecerá el derecho sustancial, los términos procesales se observaran con diligencia y su incumplimiento será sancionado, su funcionamiento será desconcentrado y autónomo (Art. $228 \mathrm{CN}$ ).

\section{ESPACIO JURÍDICO DEL DESARROLLO DE LAS ESTRATEGIAS CONTRA LA CONGESTIÓN DE DESPACHOS JUDICIALES}

Una vez ubicado el espacio teórico desde donde se orienta la discusión sobre la congestión de la justicia; pasaremos a dar desarrollo al espacio jurídico en donde se mostrara a continuación las estrategias contra la congestión de despachos judiciales desarrolladas y presentadas por distintos entes entre ellos el Consejo Superior de la Judicatura.

En el contexto teórico se hace necesario relatar los modelos jurídicos que a lo largo de la historia se han implementado al interior de la jurisdicción que comprenden la congestión judicial, organizados como se observa en el gráfico 1 .

Se puede detectar la forma en la cual se llevan a cabo los procesos judiciales dentro de un juzgado teniendo en cuenta para ello diversos factores que alteran los procedimientos mismos.

El modelo procedimental no permite hacer ninguna idea de la equidad que puede producirse con las reformas. Por ello, en los siguientes modelos aparecerán elementos y subsistemas externos al procedimiento legal y que hacen parte del sistema social.

Cabe a notar que dentro de investigación este primer modelo sirve como base para determinar cuales son los factores que dentro de la justicia civil colombiana han creado tropiezos, los cuales han traído como consecuencia fatal la congestión de la justicia aquí investigada

Este modelo se concibe a partir del incumplimiento de la funciones del sistema judicial tradicional en la solución de conflictos y procesos, en especial los causados por la congestión judicial, llevando a la sociedad a iniciar soluciones alternativas de justicia. (Ariza, 2003). 


\section{Gráfico 1. Modelo Procedimental}

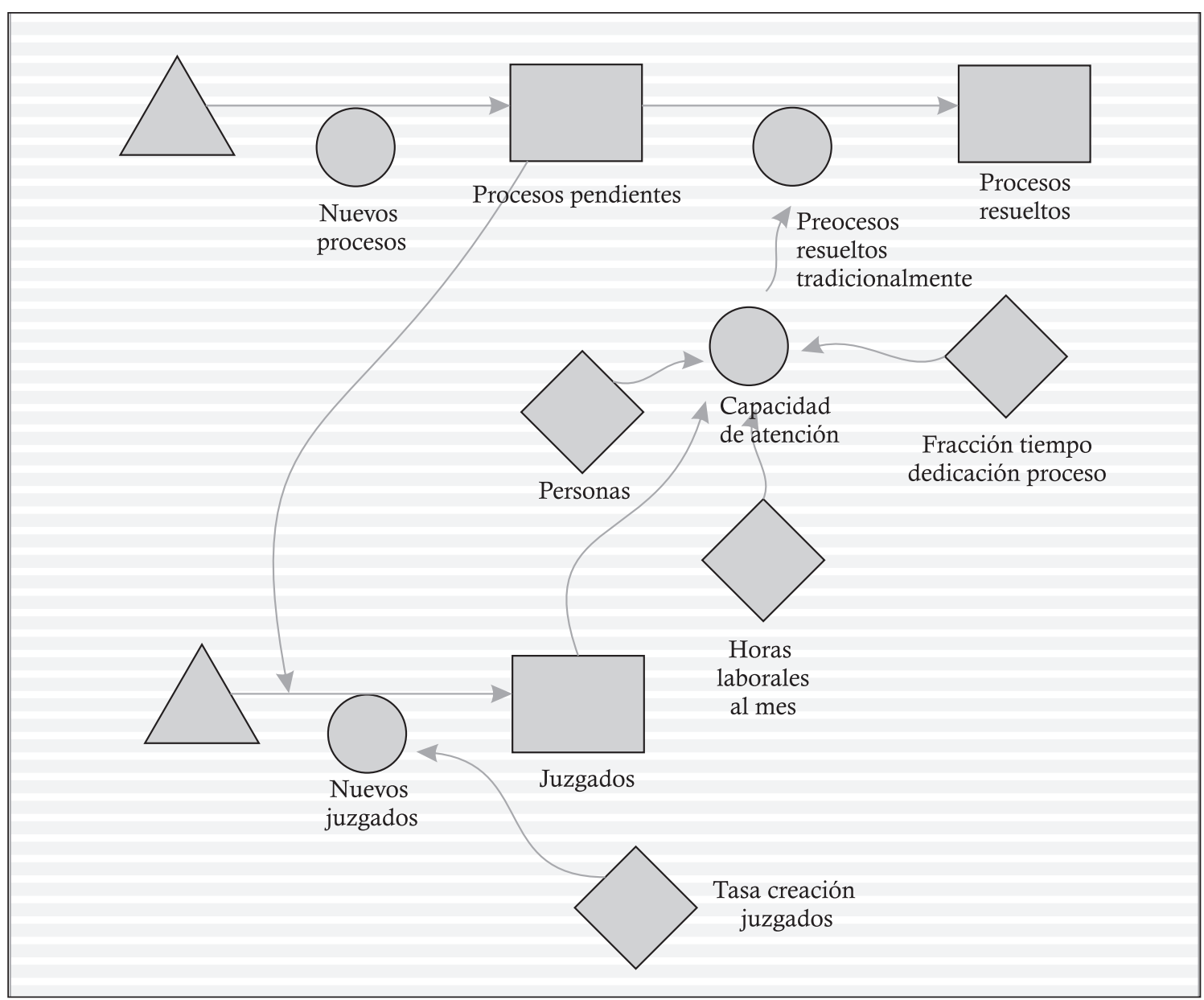

Tomado de: (Ariza, 2003)

En la congestión intervienen dos variables de nivel y cada una conforma los siguientes subsistemas: procesos legales y procesos ilegales, que son alimentados por los procesos que surgen por parte de la sociedad.

Se observa que la congestión afecta notoriamente a los procesos pendientes legalmente, es decir, en cuanto el numero de los mismos se aumenta la solución es cada vez mas lejana debido a que los recursos en el sistema legal son limitados, esto conlleva a que la ciudadanía perciba a la justicia tradicional congestionada y obliga a la sociedad a no acceder a dicho sistema, de tal forma que empiece a engrosar los procesos pendientes ilegales, siendo esta una nueva forma de búsqueda de justicia.

Este modelo dentro de nuestra investigación se convirtió en el parámetro a partir del cual determinamos, que la sociedad recurre cada vez mas a mecanismos ilegales que le permitan dar solución pronta a sus conflictos, por encontrarse la jurisdicción actualmente en estado congestión inminente. 


\section{Gráfico 2. Modelo de "Justicia" ilegal}

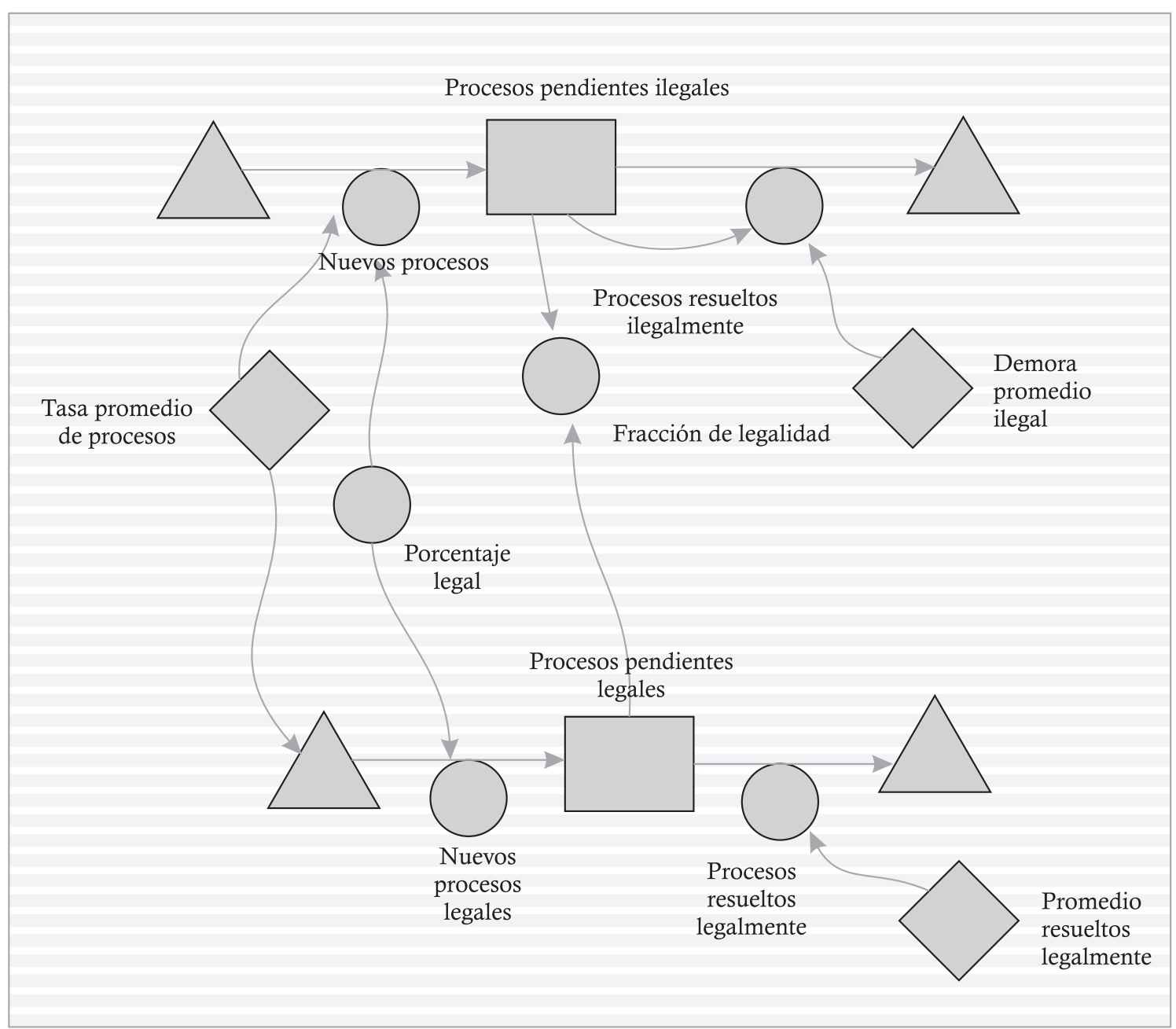

Tomado de: (Ariza, 2003)

El modelo de congestión percibida parte de los parámetros establecidos por el modelo anteriormente explicado, dando una visión mas detallada de cómo el ciclo de congestión afecta paulatinamente la percepción de la justicia por parte de la sociedad, siendo éste un ciclo de regulación del sistema legal.

En la medida que los procesos pendientes legales van creciendo indiscriminadamente por estar la ciudadanía percibiendo descongestión en el sistema, este tiende a no poder atender la solución de todos los procesos hasta un punto en el cual el empieza a regularse porque el ciudadano que accede al sistema lo nota lento para dar solución y entonces comienza a optar por la vía ilegal. Lo anterior permite comprobar que hasta este punto, el modelo se comporta razonablemente. En consecuencia el nivel de procesos pendientes empieza a regularse por medio del ciclo de congestión. 


\section{Gráfico 3. Modelo de Congestión percibida}

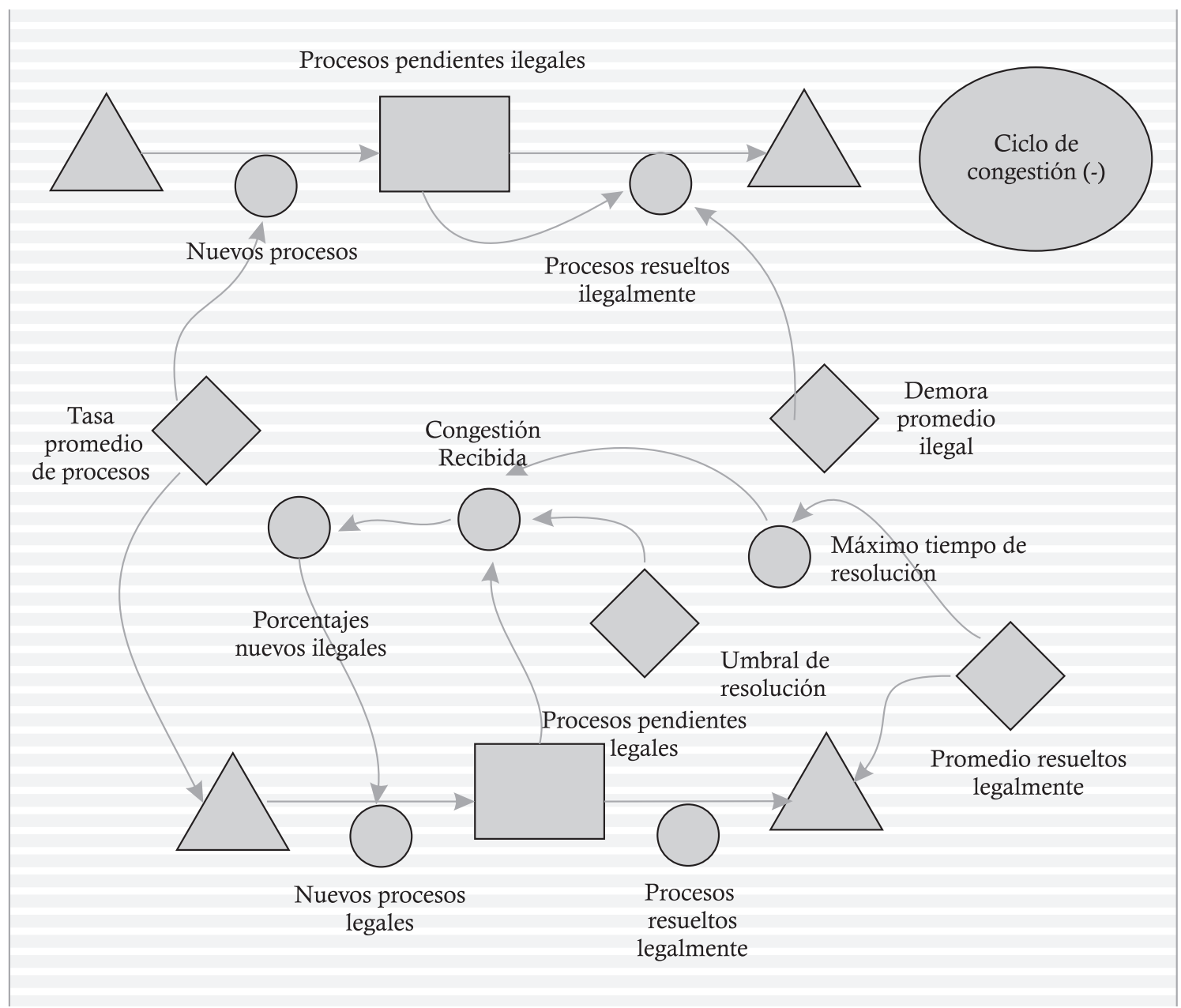

Tomado de: (Ariza, 2003)

Si la congestión judicial en materia civil se empezara regular a partir de la practica de la unificación de los términos como se propone en nuestra investigación seria cada vez mas viable ir descongestionando día a día la jurisdicción civil, lo que arrojaría como resultado una mayor credibilidad de la sociedad en sus administradores de justicia para quitar del medio aquellos mecanismo ilegales para la solución de conflictos.
Muestra como primera medida distintas formas que tiene la sociedad para acceder a la administración de justicia concibiendo un sistema tanto legal como ilegal e incluyendo un subsistema de formas alternativas de justicia.

Los mecanismos alternativos de resolución de conflictos fueron implementados por parte del gobierno dentro del marco legal para así lograr mayor participación ciudadana en el 


\section{Gráfico 4. Modelo de Procesos alternativos y Educación}

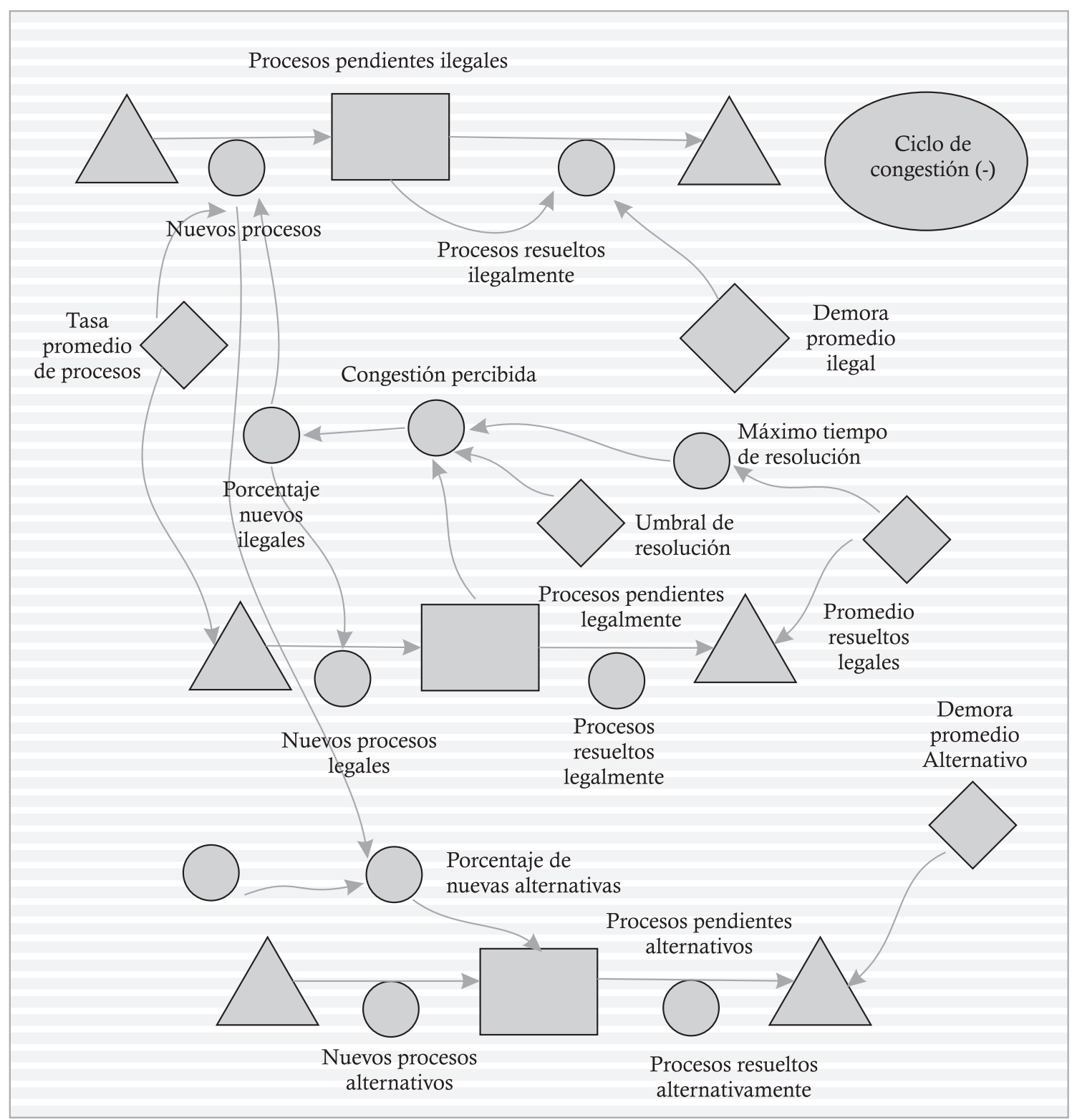

Tomado de: (Ariza, 2003)

sistema legal, para ello el Estado requiere un programa de educación a nivel judicial el cual ayude al fácil acceso al sistema por parte de la ciudadanía. Además de ello la integración de estos mecanismos alternativos de resolución de conflictos busca descongestionar el aparato judicial colombiano. Como se aprecia estos mecanismos están contemplados para funcionar con recursos ilimitados, con la interacción entre el nivel de procesos pendientes alternativos 
y la demora promedio alternativa, lo cual quiere decir que a medida que los recursos van aumentando las soluciones para ello crecen paralelamente esto es semejante a la realidad, al igual que el comportamiento de los procesos pendientes ilegales que a medida que se presentan procesos se les va dando "solución".
El elemento fundamental en este modelo es la educación de la ciudadanía, preparándola para afrontar el reto de la modernización; haciéndolos así concientes de su participación dentro del sistema.

En el ciclo se ve como los procesos que ingresan al subsistema legal van aumentando de manera

\section{Gráfico 5. Modelo final}

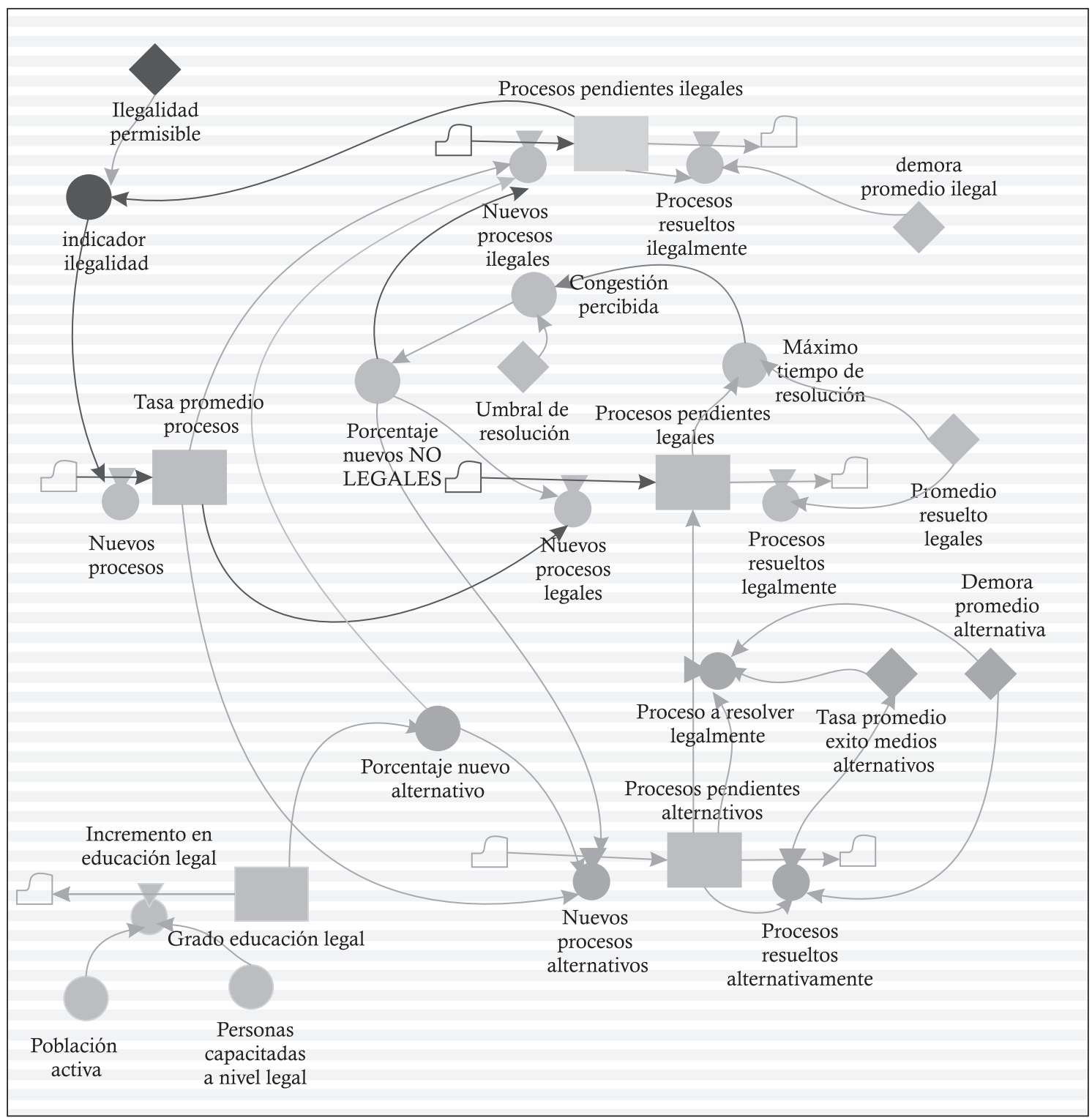

Tomado de: (Ariza, 2003) 
significativa la congestión en el mismo, a su vez dando como consecuencia que la sociedad acceda al subsistema ilegal por percibir congestión en el legal. Pero el aumento de ilegalidad inevitablemente genera delitos que aumentan el promedio de casos que llegan al sistema.

Finalmente se hace necesario señalar la elaboración y presentación del proyecto de ley numero 286/07 CAMARA Por el cual se reforma la Ley 270 de 1996 Estatutaria de la Administración de Justicia; es importante resaltar que este tipo de iniciativas son esenciales para el país sobre todo si se trata de buscar la protección efectiva de los derechos e intereses de los ciudadanos. Además, sólo en la medida en que los Estados logren cumplir a cabalidad con las funciones que le competen, entre ellas la administración de justicia, habrá instituciones con estructuras más sólida y legítimas apoyando el fortalecimiento de nuestra democracia.

\section{APLICACIÓN DEL MARCO}

Finalizada la explicación del contexto jurídico y teórico sobre la cual se enmarca la congestión de la justicia en materia civil se debe dar desarrollo al punto en donde se genera dicha congestión.

Los funcionarios judiciales deben contar hoy en día con criterios fundamentados que les permitan enfrentar el reto de combinar el apego irrenunciable a la ley con la necesidad de interpretarla y aplicarla apelando a criterios que en buena parte dependen de sus capacidades subjetivas. Para ello se requieren de dos elementos fundamentales: una sólida formación teórica y el conocimiento de la larga y rica tradición jurisprudencial colombiana.

Una de las principales causales es el desempeño de los jueces civiles; quienes como administradores de justicia no pueden con el incremento de sus funciones administrativas y operativas que se encuentran a su cargo.
Otra de las causales es el uso innecesario que hacen muchos ciudadanos del aparato judicial.

"Los problemas de la Justicia se centran fundamentalmente en la ineficacia y la ineficiencia". (CONSEJO SUPERIOR DE LA JUDICATURA, Plan de desarrollo para la justicia 1999-2002).

Según el diagnóstico de la situación judicial realizado por la Corporación Excelencia en la Justicia las problemáticas más graves ocurren en: Los procedimientos y practicas judiciales, la gestión ineficaz e ineficiente, y las restricciones al acceso; y entre los efectos de tales problemáticas tenemos: Impunidad, Congestión, Inoperancia y falta de credibilidad.

\section{Gráfico 6. Diagnóstico de la situación de Justicia en Colombia}

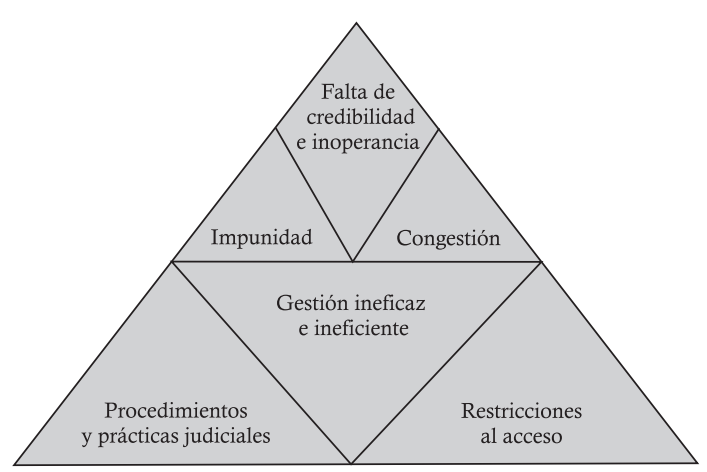

Tomado de: (Ariza, 2003)

De acuerdo a este diagnóstico y a los resultados de diferentes estudios puede decirse que la justicia formal está viviendo una crisis de credibilidad y adhesión por parte de los ciudadanos quienes recurren poco a ella, pues la perciben lenta, ineficaz para resolver los casos y castigar el delito, así como afectada en algunos casos por problemas de corrupción.

\section{CONCLUSIONES}

Sin lugar a duda nos encontramos frente a un Estado y un Consejo Superior de la Judicatura 
paquidérmico, negligentes e insolentes con el Poder Judicial, al permitir que cada día se incremente paulatinamente la morosidad de la Justicia, constituyendo así una denegación de Justicia, cuyos resultados no son otros que la impunidad y por ende la violencia.

Basta observar la anterior cronología de reformas parciales al Código de Procedimiento Civil, por lo menos las de finales del siglo veinte y las de comienzo de este, para darnos cuenta que Magistrados, Jueces, Tratadistas, Litigantes, Estudiantes de Derecho y la Sociedad en general claman por una Reforma integral al Código de procedimiento Civil, donde minimice o unifique procedimientos y términos Procesales entre otros, tal y como ya se realiza una investigación donde se sugieren algunas alternativas y reforma integral al Código de Procedimiento Civil como una de las soluciones a la actual congestión de la Justicia en materia Civil.

Uno de los actuales proyectos de Ley que cursa en el Congreso, es el adelantado por el Instituto Colombiano de Derecho Procesal, denominado Código Único de Procedimiento y otro cuya bandera es la oralidad de los procesos, sin embargo se considera que estos proyectos no son suficiente para lograr que el mandato constitucional y procesal se cumpla, esto es con una pronta y cumplida administración de justicia y así poder devolver a la ciudadanía la credibilidad en la Justicia.

Para lograr el cometido constitucional no es suficiente presentar y aprobar reformas sino van precedidas de un presupuesto digno que permita incrementar paulatinamente los cargos de Jueces y Magistrados, así como sus respectivas empleados acorde con el aumento poblacional del país, y de los conflictos civiles.

Veamos una simple muestra selectiva de tipo estadístico, practicada a cinco Juzgados Civiles del Circuito y cinco Civiles Municipales de Bogotá:

La anterior muestra nos lleva a concluir que cada año se incrementan los conflictos dado el aumento de población y por ende el porcentaje de procesos acumulados en los Despachos Judiciales en razón a la diversidad de procedimientos, términos procesales y el número de Despachos que no aumentan en proporción al crecimiento poblacional como sería lo ideal.

Tabla 1.

\begin{tabular}{cccccc}
\hline $\begin{array}{c}\text { Inventario } \\
\text { a enero de 2000 }\end{array}$ & Ingreso por reparto & Salidas & $\begin{array}{c}\text { Inventario } \\
\text { a junio de 2007 }\end{array}$ & $\begin{array}{c}\% \\
\text { En congestión }\end{array}$ \\
\hline 2000 & 2835 & 825 & 582 & 3068 & 29,45 \\
\hline 2001 & 2930 & 956 & 580 & 3106 & 39.33 \\
\hline 2002 & 2870 & 994 & 545 & 3319 & 45.17 \\
\hline 2003 & 2940 & 1018 & 512 & 3446 & 49.70 \\
\hline 2004 & 3100 & 1080 & 514 & 3666 & 52.40 \\
\hline 2005 & 3250 & 1125 & 552 & 3823 & 50.93 \\
\hline 2006 & 3400 & 1184 & 522 & 4062 & 55.91 \\
\hline 2007 & 3620 & 1222 & 391 & 4351 & 69.63 \\
\hline
\end{tabular}

Elaborado por: Dr. Luís Agapito Moreno Moreno 


\section{QUÉ ESTRATEGIAS SE PUEDEN ADOPTAR}

En 2010 Colombia habrá eliminado las barreras remanentes de acceso a la administración de justicia y estará dando plena garantía a la efectividad de los derechos, libertades y obligaciones dentro del marco del Estado social y democrático de derecho. Antes, en 2010, Colombia habrá avanzado significativamente en la organización y coordinación de la oferta de la justicia y, con base en ello, habrá reducido el indicador de congestión, que hoy se encuentra en $62,6 \%$, a $52,2 \%$ en 2010 y a $32,5 \%$ en 2019. (VISION COMLOMBIA 2019- Presidencia de la República, Editorial Planeta, y Departamento nacional de planeación).
Las estrategias que se pueden adoptar según lo establecido en el PLAN SECTORIAL DE DESARROLLO DE LA RAMA JUDICIAL 2007-2010 son:

En un nivel de contexto macro externo se deben procurar fluidas, efectivas y coordinadas relaciones inter- agénciales entre los operadores del sistema jurídico (jueces, magistrados y empleados judiciales) y las entidades que interactúan con la administración de justicia con el propósito de focalizar acciones estratégicas comunes, que garanticen el cumplimiento de los postulados misionales de la administración de justicia y del Estado.

En un nivel de contexto medio en la dimensión territorial las relaciones inter agénciales deben

Tabla 2. Garantizar una justicia eficiente

\begin{tabular}{|c|c|c|c|}
\hline Meta & Situación actual & Situación 2010 & Situación 2019 \\
\hline $\begin{array}{l}\text { (1) Racionalizar el servi- } \\
\text { cio de justicia y mejorar } \\
\text { el acceso }\end{array}$ & $\begin{array}{l}\text { Indicador de congestión } \\
\text { en } 62.6 \%\end{array}$ & $\begin{array}{l}\text { Disminución de la con- } \\
\text { gestión a } 52.2 \% \\
\text { Reducción de tiempos } \\
\text { procesales }\end{array}$ & $\begin{array}{l}\text { Disminución de la con- } \\
\text { gestión a } 32.5 \% \\
\text { Reducción de tiempos } \\
\text { procesales }\end{array}$ \\
\hline $\begin{array}{l}\text { (2) Fortalecer el sistema } \\
\text { penal y disminuir la } \\
\text { impunidad }\end{array}$ & $\begin{array}{l}\text { Actualmente reforma } \\
\text { penal en curso. } \\
\text { Inexistencia de un siste- } \\
\text { ma de defensoria pública. } \\
\text { Ausencia de un indicador } \\
\text { integral de impunidad } \\
\text { penal } \\
\text { Debilidades en el pro- } \\
\text { grama de protección de } \\
\text { testigos de la FGN }\end{array}$ & $\begin{array}{l}\text { Evaluación de reforma } \\
\text { penal } \\
\text { Sistemas de defensoria } \\
\text { pública implementado } \\
\text { Indicador integral de } \\
\text { impunidad aplicado. } \\
\text { Fortalecimiento del } \\
\text { programa de protección } \\
\text { de testigos. }\end{array}$ & $\begin{array}{l}\text { Agustes de la reforma } \\
\text { penal } \\
\text { Ajustes del sistema } \\
\text { Ajustes y seguimiento } \\
\text { Programa de protección } \\
\text { de testigos y el sistema de } \\
\text { defensoría pública. }\end{array}$ \\
\hline $\begin{array}{l}\text { (3) Mejorar el sistema } \\
\text { penitenciario y carcelario }\end{array}$ & $\begin{array}{l}\text { Niveles de hacinamiento } \\
\text { críticos } 37 \%\end{array}$ & $\begin{array}{l}\text { Disminución de la tasa } \\
\text { de hacinamineto a } 20 \% \\
\text { por ejecución de estra- } \\
\text { tegias del documento } \\
\text { Conpes } 3277 \text { de marzo } \\
15 \text { de } 2004\end{array}$ & $\begin{array}{l}\text { Inició de un nuevo plan } \\
\text { de concesión de cons- } \\
\text { trucción y operación } \\
\text { de cupos de mediana y } \\
\text { minima seguridad }\end{array}$ \\
\hline $\begin{array}{l}\text { (4) Fortalecer los sistemas } \\
\text { de información, sistema- } \\
\text { tización y telecomunica- } \\
\text { ciones del sector justicia }\end{array}$ & $\begin{array}{l}\text { No hay complementarie- } \\
\text { dad, integralidad e inte- } \\
\text { roperabilidad entre los } \\
\text { sistemas de información }\end{array}$ & $\begin{array}{l}\text { Seguimiento y ajustes al } \\
\text { desarrollo de las aplica- } \\
\text { ciones. }\end{array}$ & $\begin{array}{l}\text { Sistemas interconectados } \\
\text { e interoperables }\end{array}$ \\
\hline
\end{tabular}

Fuente línea de base: (1) UDAE C. S. de la J., 2004; (3) INPEC, 2004; Cálculos DNP-DJS-SJ.

Bogotá, D.C. Colombia - Volumen XII - No. 24 - Julio - Diciembre 2009 - ISSN 0121-182X 
procurar altos niveles de participación de quienes son objeto de decisión, esto es, las partes del proceso en las decisiones de reasignación de los derechos por parte de los operadores de los sistemas jurídicos.

En el nivel de contexto local debe procurarse la oportunidad en la reasignación de los derechos, lo que significa una planificación local armónica con la planificación macro.

Una Justicia tardía e inoportuna se torna en las peores de las injusticias.

\section{BIBLIOGRAFÍA}

Anales del Congreso, Diciembre 3 de 1986, año XXIX N 153.

ARIZA ZABALA Gerly Carolina, Análisis dinámico-sistémico de la política de modernización del sistema judicial colombiano, Grupo de Investigación en Pensamiento Sistémico Facultad de Ingeniería de Sistemas Universidad Autónoma de Bucaramanga Bucaramanga, Colombia.

ARCHICA José Antonio y ARGUELLO Alcibíades, Código de Organización Judicial y procedimiento Civil, proemio, Editorial Cromos 1924.

AZULA CAMACHO Jaime, Manual de derecho procesal civil, t. I-II, Editorial Temis, 2004.

AZULA CAMACHO Jaime, Manual de derecho procesal civil, t. III-IV y V, Editorial Temis, 2004.

CARNELUTTI Francesco, Instituciones de derecho procesal, Temis reimpresión, 2000.

CHIOVENDA Giuseppe, Principios de derecho procesal civil, Madrid, Instituto Editorial Reus, S.A., 1995
CÓDIGO DE PROCEDIMIENTO CIVIL Comentado, Legis 2008..

CÓDIGO DE PROCEDIMIENTO CIVIL, Leyer 2008.

CORTE SUPREMA DE JUSTICIA, Gaceta Judicial LXIII. 1947.

DEVIS ECHANDIA Hernando, Instituciones de derecho procesal, Parte especial, Temis, 1996.

HENAO CARRASQUILLA Oscar Eduardo, Código de procedimiento civil comentado, Leyer, 2005

JARAMILLO CASTAÑEDA Armando, Manual teórico práctico de procedimiento civil, Doctrina y ley Ltda. 2004.

LÓPEZ BLANCO Hernán Fabio, Procedimiento civil, Parte general, 9 $9^{\mathrm{a}}$ ed., Dupre, 2008.

LÓPEZ BLANCO Hernán Fabio, Procedimiento civil, Parte especial, $8^{\mathrm{a}}$ ed., Dupre, 2004.

MORALES MOLINA Hernando, Instituciones de derecho procesal, TEMIS 1998.

MORENO MORENO, Luis Agapito, Unificación de Procesos y Términos Procesales, 2009.

PARRA QUIJANO Jairo, Derecho procesal civil, Parte especial, t. II, Librería del profesional, 2005.

OSSORIO Manuel, Diccionario de Ciencias Jurídicas, Políticas y Sociales, Editorial Heliasta, 1981.

UPRIMNY Rodrigo, RODRÍGUEZ Cesar y GARCÍA VILLEGAS Rodrigo. Entre el protagonismo y la rutina: Análisis Socio jurídico de la justicia en Colombia.

VISIÓN COLOMBIA 2019, Presidencia de República, Editorial Planeta y Departamento Nacional de Planeacion. 